\title{
JPEB
}

\section{PENGARUH SELF SERVICE TECHNOLOGY (ISST) TERHADAP KEPUASAN DAN LOYALITAS : DENGAN MEDIASI RELATIONAL BENEFITS}

\author{
Yohan Wismantoro ${ }^{{ }^{*}}$ \\ Program Studi Manajemen, Fakultas Ekonomi dan Bisnis, Universitas Dian Nuswantoro \\ Jalan Nakula I No. 5-11 Semarang, Indonesia \\ *Corresponding Author : yohan.wismantoro@dsn.dinus.ac.id
}

Diterima: November 2015; Direvisi: Januari 2016; Dipublikasikan: Maret 2016

\begin{abstract}
The application of technology-based self-service in service delivery has grown rapidly in recent years, but our current understanding of customer retention and satisfaction in such contexts remains limited.This paper proposes a conceptual framework that utilizes the construct of relational benefits to explain the link between Internet-based self-service technology attributes and customer loyalty and satisfaction. The results of an empirical study using two contexts and support for a fully mediated model. That is, confidence benefits mediate the impact of perceived control and performance on customer loyalty and satisfaction, while special treatment benefits mediate the relationship of efficiency and convenience with customer loyalty and satisfaction.
\end{abstract}

Keywords: Customer Retention; Customer Loyalty; Relational Benefits; Technology-Based self-service

\begin{abstract}
ABSTRAK
Penerapan layanan mandiri berbasis teknologi dalam penyampaian layanan telah berkembang pesat dalam beberapa tahun terakhir, namun pemahaman tentang mempertahankan konsumen dan kepuasan pelanggan dalam konteks seperti itu terbatas. Makalah ini mengusulkan kerangka konseptual yang memanfaatkan konstruksi manfaat relasional untuk menjelaskan hubungan antara atribut teknologi self-service berbasis internet, loyalitas pelanggan dan kepuasan. Hasil studi empiris yang menggunakan dua konteks dan mendukung model dimediasi. Artinya, manfaat kepercayaan memediasi dampak pengendalian dan kinerja yang dirasakan pada loyalitas dan kepuasan pelanggan, sedangkan manfaat perlakuan khusus memediasi hubungan efisiensi dan kenyamanan dengan loyalitas pelanggan dan kepuasan.
\end{abstract}

Kata Kunci: Retensi Pelanggan; Kesetiaan Pelanggan; Manfaat Relasional; Berbasis Teknologi Swalayan 


\section{PENDAHULUAN}

Kebutuhan akan informasi yang cepat serta mudah dijangkau oleh semua lapisan masyarakat membuat internet sebagai media sosial sangat diperlukan dan menjadi sangat penting.Hal tersebut juga menjadi peluang bisnis untuk memanfaatkan kemajuan teknologi internet sebagai sarana penunjang keberhasilan suatu bisnis, serta menjadi trend bisnis digital.Trend bisnis digital(e-commerce) adalah dimana pengguna teknologi digital dapat mencapai tujuan pemasaran, termasuk upaya-upaya dalam pengembangan konsep pemasaran, berkomunikasi dalam jaringan global serta merubah cara perusahaan untuk melakukan bisnis dengan pelanggan (Hill and Tobs, 2011; Lounsbury et.al, 2012). E-commerce memberikan banyakemudahan bagi para pelaku bisnis, khususnya dalam hal untuk berhubungan dengan pelanggan, penyampaian informasi, membantu untuk memahami pelanggan dengan lebih baik (Rodrigues, 2015; Sharma, 2016). E-commerce juga menuntut perusahaan untuk dapat lebih kreatif dalam hal design, pengembangan, periklanan dan penjualan agar dapat menarik minat pelanggan.

Fenomena diatas menunjukkan bahwa keputusan pelanggan untuk menjalin hubungan kerjasama jangka panjang dengan suatu perusahaan semakin ditentukan oleh bagaimana penilaian pelanggan terhadap produk inti dan aspek relasional dalam suatu pertukaran. Artinya, disatu sisi konsumen selalu membandingkan antara interaksi interpersonal dibandingkan dengan performa produk yang ditawarkan. Konsep seperti ini dalam literatur pemasaran disebut dengan relational benefits, yang memungkinkan para pelanggan terlibat dalam hubungan jangka panjang dengan penyedia layanan dan personilnya. Literatur-literatur yang berkembang mengenai pemasaranhubungan (relationship marketing) dimulai dengan pertanyaan jenis manfaat relasional seperti apa yang dapat digunakan untuk mempertahankan hubungan jangka panjang dengan perusahaan (Barnes, 1994; Gwinner et.al, 1998; Reynolds dan Beatty, 1999).

Hennig-Thurau et.al. (2002) mengkonsepkan relational benefit merupakan anteseden dari kualitas suatu layanan . Hasil dari penelitian ini juga menunjukkan bahwa variabel social benefit dan confidence relasional benefitsmempunyai pengaruh langsung dan signifikan terhadap loyalitas pelanggan dan word-of-mouth marketing.Oleh sebab itu, relational benefityang dirasakan konsumen dapat menimbulkan dampak yang menguntungkan bagi penyedia layanan. Namun, dengan semakin banyak transaksi yang dilakukan dengan tidak adanya kontak dengan karyawan (melalui teknologi Internet Self Service Technology, contohnya Lazada.com; Blibli.com) pertimbangan penting adalah apakah relational benefittetap relevan dalam konteks online. Artinya, dengan tidak adanya kontak antar manusia, aspek relasional dari pertukaran melalui Internet dapat mempengaruhi secara positif atau negatif untuk terus mendorong loyalitas dan kepuasan pelanggan.

Meskipun manfaat yang dirasakan dari self-service berbasis internet (ISST) semakin bertambah baik, tetap ada potensi kerugian untuk mengganti kontak personal dengan interaksi berbasis teknologi(Barnes et.al, 2000;. Gremler dan Gwinner, 2000). Menurut Gutek et.al (2000), pelanggan yang mempunyai hubungan yang baik dengan perusahaan akan lebih setia dan lebih bersedia untuk memberikan rekomendasi kepada orang lain. Hubungan interpersonal yang terjalin seperti ini jauh lebih penting bagi konsumen dibandingkan pemberian occasional priceatau layanan khusus lainnya (Gwinner et.al., 1998).

Jika bukan karena aspek relational benefityang sudah diterangkan diatas, maka kemungkinan penyebabnya adalah faktor-faktor lain yang berperan dalam mengembangkan loyalitas pengguna Internet Self Service Technology. Beberapa peneliti telah menyarankan bahwa faktor-faktor seperti: performa teknologi; kenyamanan yang diterima dari teknologi; persepsi dapat mengontrol penggunaan teknologi; dan efisiensi penggunakan teknologi, semua akan positif mempengaruhi adopsi terhadap self-service technology (Dabholkar, 1996; Meuter et.al, 2000). Dalam tulisan ini, akan dibahas peran relational benefits yang mediasi 
hubungan empat faktor (ISST) dengan loyalitas dan kepuasan pelanggan. Selanjutnya akan diajukan hipotesis mengenai peran mediasi relational benefitsantara atribut ISST terhadap loyalitas dan kepuasanpelanggan. Berdasarkan tinjauan pustaka dan hipotesis, akan disajikan model teoritis hubungan kausalitas, yang dikumpulkan data survei yang dikumpulkan dari pengguna Lazada.com

\section{TINJAUAN PUSTAKA \\ Relational Benefits}

Hubungan yang kuat antara pelanggan dan perusahan sudah dibuktikan dan didokumentasikan secara runtut oleh peneliti-peneliti sebelumnya (misalnya Aaker, 1992; Clark dan Payne, 1994; McKenna, 1991; Reichheld, 1993, 1996). Mengacu pada peneliti terdahulu tentang manfaat yang diperoleh konsumen dalam hubungan jangka panjang dengan perusahaan (Barnes, 1994; Bendapaudi dan Berry, 1997; Berry, 1995), Gwinner et.al. (1998) mengembangkan 3 manfaat utama relational benefits produk inti jasa :

(1) Confidence benefits;

(2) social benefits; dan

(3) special treatment benefits.

Confidence benefit menggambarkan pengurangan ketidakpastian dalam transaksi dan peningkatan harapan yang realistis untuk suatu layanan. Social benefitsmenggambarkan aspek emosional dari hubungan dan fokus pada pengakuan pribadi dari pelanggan dengan karyawan dan pengembangan persahabatan antara pelanggan dan karyawan. Sedangkan special treatment benefitsmerupakan manfaat yang dirasakan konsumen baik secara ekonomi maupun layanan khusus (kustomisasi). Pemberian penawaran dan perlakuan khusus yang diberikan perusahaan ke konsumen adalah untuk membedakan antara konsumen yang special dan konsumen biasa (non-relasional). Pengembangan program ini masih didasarkan pada relational benefits atas dasar hubungan langsung (face-to-face encounters), apakah pelanggan memandang relational benefits dalam interaksi penyedia layanan berbasis teknologi masih belum diketahui.

Gwinner et.al(1998); Hennig-Thurau et.al., (2002) juga mengembangkanhubungan positif antara tiga jenis manfaat relasional dan loyalitas pelanggan. Terlepas dari jenis layanan, confidence benefits menjadi jenis yang paling penting dari manfaat hubungan secara langsung / face to face encounter (Gwinner et.al., 1998)terhadap loyalitas terutama melalui kepuasan (Hennig- Thurau et.al., 2002). Mengingat bahwa masalah keamanan dan privasi dalam transaksi online adalah perhatian utama bagi konsumen (Zeitheraml dkk., 2000), persepsi confidence benefits dalam transaksi online memiliki efek positif pada niat seseorang untuk tetap berada dalam suat hubungan.

Berkembangnya teknik data warehousing dan data mining untuk merekam dan menganalisis perilaku belanja konsumen memungkinkan penyedia layanan berbasis web untuk memberikan penawaran layanan yang disesuaikan untuk pelanggan mereka. Informasi tersebut juga dapat dimanfaatkan oleh penyedia layanan berbasis Web untuk membuat rekomendasi yang cocok dengan target konsumen. Special treatment benefitsmemampukan pelanggan dapat berinteraksi dengan penyedia layanan dan diperkirakan memiliki efek positif pada niat seseorang untuk tetap menjalin hubungan (yaitu kesetiaan mereka kepada penyedia layanan). Karena self-service teknologi berbasis internet secara definisi mengecualikan interaksi dengan pihak lain, tidak ada kesempatan untuk mengembangkan social relational benefitsseperti yang sudah dijelaskan dalam penelitian sebelumnya. Untuk alasan ini, penelitian ini membatasi pada confidencedan special treatment benefits. Berikut ini hipotesis yang diajukan: 
H1: Confidence benefits mempunyai pengaruh positif dan signifikan terhadap customer loyalty and satisfaction.

$\mathrm{H} 2$ : Special treatment benefits berpengaruh positif dan signifikan terhadap customer loyalty dan satisfaction.

H3 : Satisfaction berpengaruh positif dan signifikan terhadap customer loyalty.

\section{Internet-Based Self-Service Attributes}

Interaksi berbasis internet dan applikasi e-commerce menghasilkan pelayanan, produk dan informasi yang terus tumbuh secara cepat. Dalam hal ini, penyedia jasa online barang dan jasa memainkan peranan yang penting dalam pengembangan aplikasi yang membantu pelanggan memilih berbagai produk dan jasa yang diinginkan baik melalui pilihan produk/jasa, pengadaan informasi produk, melakukan pembelian, dan pelacakan pesanan. Contohnya adalah Lazada.com, Blibli.com, Dinomarket, traveloka dsb. Dalam konteks marketspacedimana produk dan jasa tersedia secara digital dan dapat disampaikan melalui saluran berbasis informasi (Rayport dan Sviokla, 1995), pelanggan memiliki kemampuan untuk melayani diri mereka sendiri tanpa perlu kontak interpersonal dengan karyawan sebuah perusahaan. Evaluasi pelanggan dari atribut yang terkait dengan teknologi self-service Internet dianggap penting dalam menentukan penggunaan selanjutnya. Ada empat atribut yang telah dibahas dalam literatur sebelumnya. Banyak literatur teknologi self-service yang muncul telah difokuskan pada niat konsumen untuk mengadopsi atau terus menggunakan opsi berbasis teknologi (Davis, 1986; Davis et.al,1992). Berikut ini empat atribut yang akan sebagai faktor penting dalam adopsi aplikasi self-service berbasis internet dapat mempengaruhi confident dan special treatment benefits.

\section{Perceived control}

Penelitian sebelumnya telah membahas pentingnya kontrol dianggap sebagai faktor penting yang mengarah konsumen untuk mengadopsi bentuk self-service dari produk dan layanan pengiriman (Langeard et,al., 1981). Konstruk Variabel kontrol didasarkan pada penilaian seseorang dari kemampuan mereka sendiri untuk menentukan pembelian bagi dirinya sendiri tentang apa yang ditawarkan oleh suatu perusahaan (Lee dan Allaway, 2002). Faktor ini mendorong penggunaan internet dan loyalitas dengan memungkinkan konsumen untuk menyesuaikan layanan yang menawarkan untuk memenuhi kebutuhan khusus mereka. Persepsi konsumen terhadap konstruk kontrol diharapkan akan mengakibatkan peningkatan benefit karena pengendalian mengarah untuk memiliki prediktabilitas yang lebih besar terjadinya suatu pertukaran

H4: Perceived controlsebagai derivatif dari Internet self-service technology (ISST) mempunyai pengaruh positif dan signifikan terhadap confidence benefits.

\section{Performance}

Konsisten dengan Dabholkar (1994), salah satu konstruk yang membentuk ISST adalah performance. Performace dalam teknologi self-service berbasis internet diartikan bagaimana teknologi dapat beroperasi secara akurat dan dependen. Pengaruhnya variabel ini terhadap kepuasan adalah kinerja yang handal dan akurat dari suatu teknologi self-service berbasis Internet dapat membangun perasaan confidence, meningkatkan persepsi kepercayaan, yang pada gilirannya akan berdampak pada kepuasan dan loyalitas .

H5: Performance dari Internet self-service technology mempunyai pengaruh positif dan signifikan terhadap confidence benefits

\section{Convenience}


Yohan Wismantoro: Pengaruh Self Service Technology (ISST) Terhadap Kepuasan Dan Loyalitas : Dengan Mediasi Relational Benefits

Kenyamanan (convenience) mengacu pada kemampuan untuk menggunakan ISST dalam bertransaksi tidak dibatasi oleh tempat dan waktu. Meuter et.al. (2000), Szymanski dan Hise (2000) sekali lagi menyatakan bagaimana ini atribut kenyamanan yang dirasakan konsumen akan berdapkan pada kepuasan dan loyalitas. Peningkatan kenyamanan dalam bentuk penyediaan akses setiap saat dan di banyak tempat diharapkan akan memiliki pengaruh positif pada persepsi yang dirasakan konsumen. Special treatment benefitsini akan berdampak loyalitas dan kepuasan, yang akan memediasi hubungan antara outcomedan convenience.

H6: Internet self-service technology convenience mempunyai mempengaruhi positif dan signifikan terhadap treatment benefits

\section{Efficiency}

Atribut efisiensi didasarkan pada gagasan untuk mengurangi baik waktu yang digunakan maupun frekuensi tatap muka antara pembeli dan provider ketika memanfaatkan Internet Self Service Technlogoy (ISST). Aplikasi elektronik ini digunakan untuk mempercepat transaksi di berbagai aktivitas bisnis (tiket penerbangan, penyewaan mobil, dan hotel check-in dsb). Konsumen akan cenderung memiliki persepsi peningkatan special treatment benefits sebagai akibat efisiensi yang dirasakan karena menggunakan teknologi ini. $\mathrm{H} 7$ : Internet self-service technology eficiency mempunyai pengaruh positif dan signifikan terhadap special treatment benefits.

\section{METODE PENELITIAN}

Berdasarkan literatur diatas, model akan menempatkan variabel relational benefits sebagai variabel mediasi antara atribut ISST terhadap variabel outcome (satisfaction dan Loyalty) seperti gambar berikut :

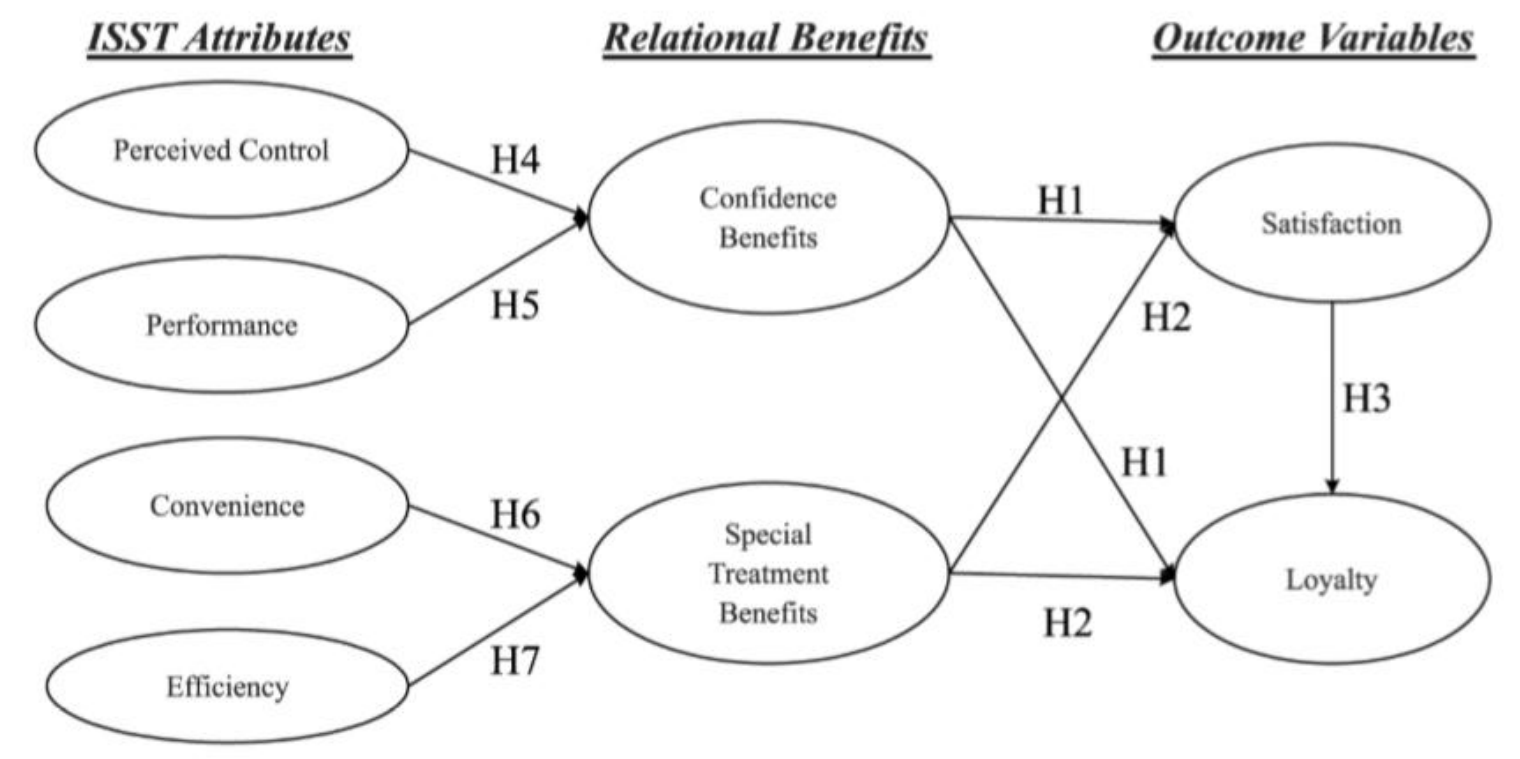

Gambar 1. Model Hipotesis

Konstruks Internet self-service technology (ISST) terdiri dari 4 dimensi, yaitu perceived control, performance, convenience dan efficiency. Populasi penelitian ini adalah seluruh konsumen/pelanggan LAZADA di Semarang. Penelitian ini menggunakan teknik 
Non Probability Sampling dengan menggunakan Purposive Sampling. Sampel yang diambil sebesar 150 responden, dengan pertimbangan sebagai berikut:

a. Berusia lebih dari 17 tahun

b. Merupakan pelanggan/konsumen baru yang akan menggunakan jasa belanja online LA ZADA.

c. Telah melakukan belanja online secara berulang

\section{HASIL DAN PEMBAHASAN \\ Uji Kelayakan Model}

Model yang digunakan untuk menguji model kausalitas adalah Struktural Equaltion Modelling (SEM). Melalui analisis Full Model akan terlihat ada tidaknya kesesuaian model dan hubungan kausalitas yang dibangun dalam model yang diuji. Setelah melalui measurement model dianalisis melalui confirmatory factor analysis dan dilihat bahwa masing-masingvariabel dapat digunakan untuk mendefinisikan sebuah konstruk laten, maka sebuah Full StructuralEquation Modeldapat dianalisis. Hasil pengolahan AMOS untuk model penelitianini adalah sebagai berikut:

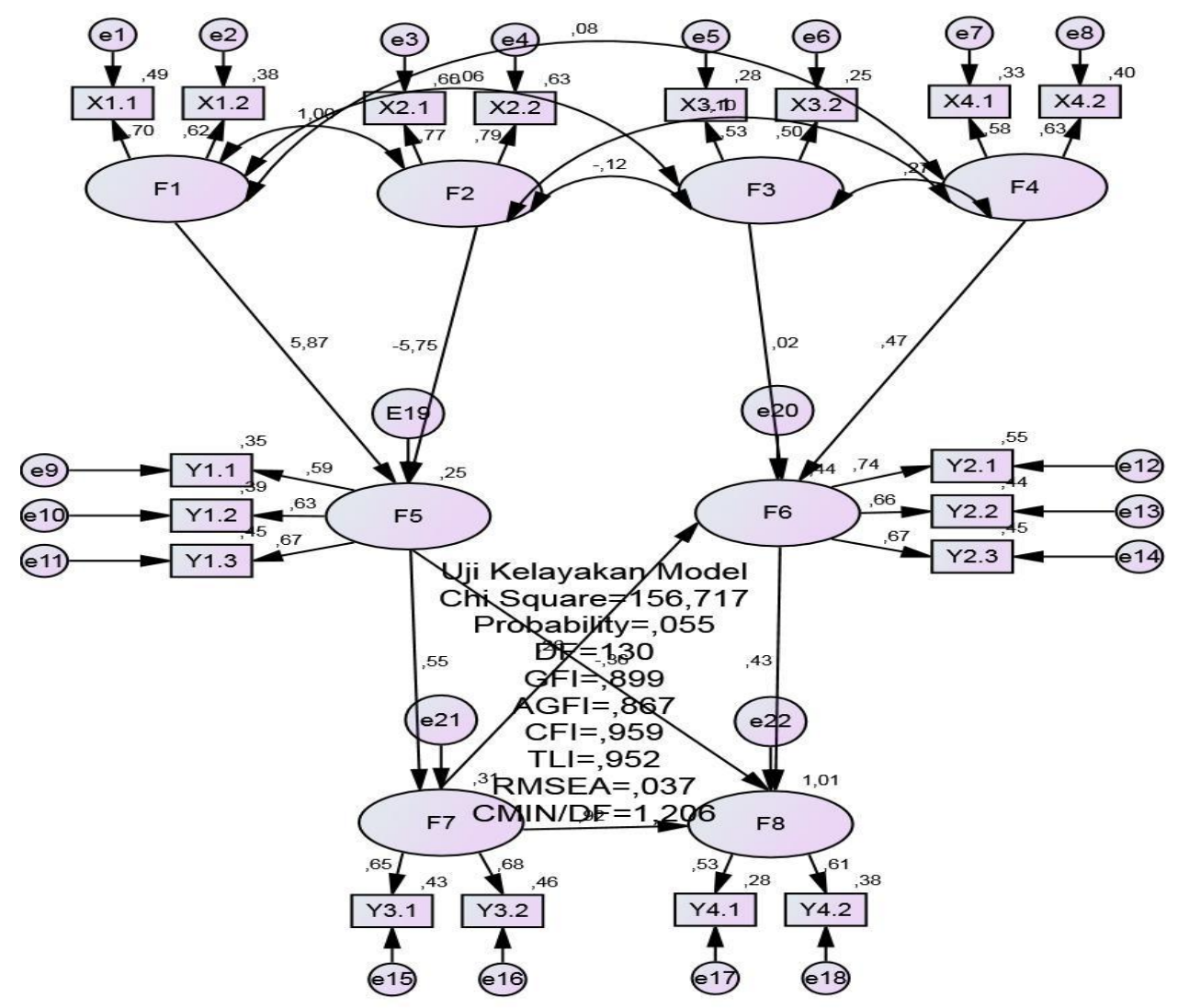

Gambar 2. Konstruk Full Structural Equation Model

Uji Kelayakan Model (Goodness-of-Fit Test) 
Yohan Wismantoro: Pengaruh Self Service Technology (ISST) Terhadap Kepuasan Dan Loyalitas : Dengan Mediasi Relational Benefits

Uji terhadap kelayakan model menunjukkan bahwa model ini sesuai dengan data fit terhadap data yang digunakan dalam penelitian adalah seperti dilihat dalam Tabel 1 berikut ini:

Tabel 1. Evaluasi Kriteria Goodness-of-fit Indices

\begin{tabular}{lccc}
\hline \multicolumn{1}{c}{ Goodness-of-fit Index } & Cut-off Value & Hasil Data & Evaluasi \\
\hline $\boldsymbol{X}^{2}$ (Chi-Square) & & 156,715 & Baik \\
Significance & $\geq 0.05$ & 0,055 & Baik \\
Probability & & & \\
GFI & $\geq 0.90$ & 130 & Baik \\
AGFI & $\geq 0.90$ & 0,899 & Marjinal \\
CFI & $\geq 0.95$ & 0,959 & Baik \\
TLI & $\geq 0.95$ & 0,952 & Baik \\
RMSEA & $\leq 0.08$ & 0,037 & Baik \\
CMIN/DF & $\leq 2.00$ & 1,206 & Baik \\
\hline
\end{tabular}

Tabel 1. menunjukkan hasil analisis pengolahan data, terlihat bahwa semua konstruk yang digunakan untuk membuat sebuah model penelitian, pada proses analisis faktor konfirmatori telah memenuhi kriteria goodness-of-fit yang telah ditetapkan. Nilai probability pada analisis ini menunjukkan nilai diatas batas signifikansi yaitu sebesar 0,055 atau diatas 0,05 menunjukkan bahwa tidak terdapat perbedaan antara matriks kovarians sampel dan matriks kovarian populasi. Hal ini berarti, tidak terdapat perbedaan antara matriks kovarian sampel dengan matriks kovarian populasi yang diestimasi dan karena itu model ini dapat diterima. Diperkuat dengan indeks-indeks kelayakan model seperti nilai GFI sebesar $130(\geq$ 0.90), nilai AGFI sebesar $0,899(\geq 0.90)$, nilai CFI sebesar $0,959(\geq 0.95)$, nilai TLI sebesar $0,952(\geq 0.95)$, nilai RMSEA sebesar 0,037 $(\leq 0.08)$, dan nilai CMIN/DF sebesar 1,206 $(\leq$ 2.00), memberikan informasi yang cukup untuk dapat diterimanya hipotesis unidimensionalitas bahwa variabel-variabel diatas dapat mencerminkan variabel yang dianalisis.

Hasil pengujian terhadap nilai-nilai muatan faktor (Loading Factor) untuk masingmasing indikator yang dilakukan adalah untuk mengetahui apakah sebuah variabel dapat digunakan untuk mengkonfirmasi bahwa variabel tersebut bersama-sama dengan variabel lainnya menjelaskan sebuah variabel laten yang dikaji dengan regression weight yang dihasilkan oleh model tersebut sebagai berikut:

\section{Tabel 2. Regression Weight}

\begin{tabular}{|c|c|c|c|c|c|c|c|}
\hline & & & Estimate & S.E. & C.R. & $\mathbf{P}$ & Label \\
\hline Confident benefit & $<--$ & Perceived control &,- 320 & ,460 &,- 695 & ,487 & par_1 \\
\hline Confident benefit & $<--$ & Performance & 3,014 & 1,090 & 2,765 & ,006 & par_2 \\
\hline Confident benefit & $<--$ & $\begin{array}{l}\text { Customer } \\
\text { satisfaction }\end{array}$ & ,706 &, 143 & 4,930 & $* * *$ & par_5 \\
\hline $\begin{array}{l}\text { Special treatment } \\
\text { benefit }\end{array}$ & $<--$ & Conveniene & ,036 & ,235 &, 154 & ,878 & par_3 \\
\hline $\begin{array}{l}\text { Special treatment } \\
\text { benefit }\end{array}$ & $<--$ & Efficiency & ,620 & ,222 & 2,800 & ,005 & par_4 \\
\hline $\begin{array}{l}\text { Special treatment } \\
\text { benefit }\end{array}$ & $<--$ & $\begin{array}{l}\text { Costomer } \\
\text { satisfaction }\end{array}$ & ,245 & , 159 & 1,538 & ,124 & par_7 \\
\hline
\end{tabular}




\begin{tabular}{lllrrrrr}
\hline Customer Loyalty & $<---$ & $\begin{array}{l}\text { Confidence benefit } \\
\text { Customer Loyalty }\end{array}$ & $<--, 436$ &, 226 & $-1,927$ &, 054 & par_6 \\
& & $\begin{array}{l}\text { Special treatment } \\
\text { benefit }\end{array}$ &, 391 &, 178 & 2,198 &, 028 & par_8 \\
Customer Loyalty & $<---$ & $\begin{array}{l}\text { Customer } \\
\text { satisfaction }\end{array}$ &, 777 &, 193 & 4,031 & $* * *$ & par_9 \\
\hline
\end{tabular}

Pada tabel 2, melalui pengamatan terhadap C.R. terlihat bahwa semua koefisien regresi secara signifikan tidak sama dengan nol sehingga hipotesis nol dapat ditolak, maka hipotesis alternatif yang menyatakan bahwa masing-masing hipotesis mengenai hubungan kausalitas yang disajikan dalam model dapat diterima.

Dari konstruk model penelitian, variabel mediasi yaitu Relational Benefit yang terdiri dari variabel confindent benefit dan special treatment benefit dapat diterangkan sebagai berikut : confident benefit tidak berpengaruh terhadap variabel outcomes yaitu variabel satisfaction dan variabel Loyalty. Sedangkan variabel special treatment benefit tidak berpengaruh terhadap variabel satisfaction, namun berpengaruh terdahap positif dan signifikan terhadap variabel Loyalty. Sedangkan variabel outcome, yaitu satisfaction menunjukkan hasil yang positif dan signifikan terhadap variabel Loyalty.

Pengaruh variabel ISST terhadap variabel mediasi Relational Benefits dapat ditunjukkan sebagai berikut : perceived control tidak berpengaruh terhadap confident benefit, namun performace berpengaruh positif dan signifikan terhadap confident benefit. Selanjutnya dua variabel ISST yang lain yaitu convenience tidak berpengaruh terhadap variabel mediasi special treatment benefits, sedangkan variabel efficiency menunjukkan hasil positif dan signifikan terhadap variabel mediasi special treatment benefits.

Hasil penelitian ini menunjukkan bahwa tidak semua variabel ISST yaitu perceived control, performance, convenience dan efficiency berpengaruh terhadap variabel relational benefits. Dalam kasus ini, konsumen pengguna situs e-commerce Lazada lebih mementingkan faktor performace dan efficiency. Demikian juga kalau ditinjau dari variabel mediasi, ternyata hanya variabel special treatment benefit yang mempunyai pengaruh positif dan signifikan terhadap variabel outcome-nya. Fenomana ini menunjukkan bahwa pelanggan yang mengakses dan bertransaksi di situs e-commerce Lazada lebih merasakan manfaat secara langsung dengan memanfaatkan teknologi ISST yang ada untuk mencapai kepuasan dan loyalitas pelanggan.Oleh sebab itu persepsi confidence benefits dalam transaksi online tetap memiliki efek positif pada niat seseorang untuk tetap berada dalam suat hubungan. Sedangkan dari variabel outcome, semakin mempertegas bahwa variabel kepuasan berpengaruh secara positif dan signifikan terhadap variabel loyalitas, mengingat bahwa masalah keamanan dan privasi dalam transaksi online adalah perhatian utama bagi konsumen (Zeitheraml et.al., 2000; Rodrigues, 2015; Sharma, 2016).

\section{SIMPULAN}

Dari hasil penelitian diatas dan merefer beberapa penelitian terbaru di industri jasa menunjukkan bahwa dukungan dan peran penting relational benefitsyang mempengaruhi intensitas loyalitas konsumen, word-of-mouth behavior, komitmen terhadap organisasi, dan kepuasan terhadap penyedia layanan (Gwinner et.al., 1998 ; Hennig-Thurau et.al, 2002). Temuan penelitian juga menunjukkan bahwa relational benefits merupakan mekanisme mediasi melalui atribut-atribut ISST yang berdampak pada kepuasan dan loyalitas konsumen. Dengan demikian, studi ini dapat disimpulan bahwa aspek relasional dalam pertukaran merupakan bagian penting dalam pemahaman tentang loyalitas dan kepuasan pelanggan. 
Yohan Wismantoro: Pengaruh Self Service Technology (ISST) Terhadap Kepuasan Dan Loyalitas : Dengan Mediasi Relational Benefits

\section{DAFTAR PUSTAKA}

Aaker, D.A. 1992. The Value Of Brand Equity. Journal of Business Strategy. 19: 27-32

Bendapaudi, N. and Berry, L.L. 1997. Customers' Motivations For Maintaining Relationships With Service Providers. Journal of Retailing. 73 (1): 15-37.

Barnes, J.G. 1994. The Issue Of Establishing Relationships With Customersin Servicecompanies: When Are Relationships Feasible And What Form Should They Take?, Proceedings. Presented at the 3rd Annual Frontiers in Services Conference, Owen Graduate School of Management, Vanderbilt University, Nashville, TN.

Barnes,J.G., Dunne,P.A. and Glynn, W.J. 2000. Self-Service And Technology:Unanticipated And Unintended Effects On Customer Relationships. in Swartz, T.A. and Iacobucci, D. (Eds).

Berry, L.L. 1995. Relationship Marketing Of Services - Growing Interest, Emerging Perspectives. Journal of the Academy of Marketing Science. 23: 236-45.

Clark, M. and Payne, A. 1994. Achieving Long-Term Customer Loyalty: A Strategic Approach. Working Paper. Centre for Services Management, Cran eld School of Management, Cran eld.

Dabholkar, P.A. 1994. Technology-Based Service Delivery: A Classi Cation Scheme For Developing Marketing Strategies. in Swartz, T.A., Bowen, D.E. and Brown, S.W. (Eds), Advance in Services Marketing and Management, JAI Press, Greenwich, CT, pp. 241-71.

Dabholkar, P.A. 1996. Consumer Evaluations Of New Technology-Basedself-Service Options: An Investigation Of Alternative Models Of Service quality. International Journal of Research in Marketing. 13 (1): 29-51

Davis, F.D. 1986. Technology Acceptance Model For Empirically Testing New End User Information System: Theory And Results. Dissertation. Cambridge: Massachusetts Institute of Technology.

Davis, F.D., Bagozzi, R.P. and Warshaw, P.R. 1992. Extrinsic And Intrinsic Motivation To Use Computers In The Workplace. Journal of Applied Social Psychology. 22.(14): 1109-301992.

Gwinner,K.P.,Gremler,D.D.and Bitner,M.J. 1998. Relationalbene ts in serviceindustries:the customer's perspective. Journal of the Academy of Marketing Science. 26(2): 101-14.

Gremler, D.D. and Gwinner, K.P. 2000. Customer-Employee Rapport In Service Relationships. Journal of Service Research. 3 : 82-104.

Gutek, B.A., Cherry, B., Bhappu, A.D., Schneider, S. and Woolf, L. 2000. Features Of Service Relationships And Encounters. Work and Occupations. 27 (3): 319-52

Hennig-Thurau, T., Gwinner, K.P. and Gremler, D.D. 2002. Understanding Relationship Marketing Outcomes: An Integration Of Relational Bene Ts And Relationship Quality. Journal of Service Research. 4 (3): 230-47.

John W. Lounsbury, Nancy Foster Patrick C. Carmody, Ji Young Kim, Lucy W. Gibson, Adam W. Drost. 2012. Key Personality Traits And Career Satisfaction Of Customer Service Workers. Managing Service Quality: An International Journal. 22 (5): 517 - 536

Langeard, E., Bateson, J.E.G., Lovelock, C.H. and Eiglier, P. 1981. Marketing of Services: New Insights from Consumers and Managers. Report. 81-104. Cambridge: Marketing Science Institute.

Lee,J. and Allaway, A. 2002. Effects Of Personal Control On Adoption Of Self-Service Technology Innovations. Journal of Services Marketing. 16 (6): 553-72.

McKenna, R. 1991. Marketing In Everything. Harvard Business Review. 69: 65-79. 
Meuter, M.L., Ostrom, A.L., Roundtree, R.I. and Bitner, M.J. 2000. Self-Service Technologies: Understanding Customer Satisfaction With Technology-Based Service Encounters. Journal of Marketing. 64 (3): 50-64.

Rayport, J.F. and Sviokla, J.J. 1995. Exploiting The Virtual Value Chain. Harvard Business Review. 73: 14-24.

Reynolds, K.E. and Beatty, S.E. 1999. Customer Benefits And Company Consequences Of Customer-Salesperson Relationships In Retailing. Journal of Retailing. 75(1): 11-32.

Rodrigues, Luiza Cristina Alencar; Filipe J. Coelho, Carlos M. P. Sousa. 2015. Control Mechanisms And Goal Orientations: Evidence From Frontline Service Employees. European Journal of Marketing. 49 (3): 350 - 371

Sally Rao Hill and Alastair Tombs. 2011. The Effect Of Accent Of Service Employee On Customer Service Evaluation. Managing Service Quality: An International Journal. 21 (6): $649-666$

Sharma, Piyush; Zhan Wu; Yong Su. 2016. Role Of Personal Cultural Orientations In Intercultural Service Encounters. Journal of Services Marketing. 30 (2): 223 - 237

Szymanski, D.M. and Hise, R.T. 2000. E-Satisfaction: An Initial Examination. Journal of Retailing. 76 (3): 309-22.

Zeithaml, V.A., Parasuraman, A. and Malhortra, A. 2000. A conceptual framework for understandinge-servicequality: implications for future researchand managerialpractice. Working Paper. No. 00-115. Cambridge: Marketing Science Institute. 